\title{
Analysis of the Cell Walls of Ceramic Foams by X-ray Microtomography
}

\author{
Rodrigo Nagata ${ }^{1}$ \\ State University of Londrina \\ Caixa Postal 6001, 86051-990- Londrina, PR, Brazil \\ E-mail: rodrigo_nagata@yahoo.com.br
}

\section{Carlos Roberto Appoloni}

State University of Londrina

Caixa Postal 6001, 86051-990 - Londrina, PR, Brazil

E-mail: appolonieuel.br

\section{Leonardo Carmezini Marques}

State University of Londrina

Caixa Postal 6001, 86051-990 - Londrina, PR, Brazil

E-mail: leonardocmeuel.br

\begin{abstract}
Ceramic foams have a wide range of applications (heat exchangers, liquid metal filters, porous electrodes, composite of rocket nozzles, etc.) due their properties, such as high melting temperature, high porosity, low thermal conductivity and low density. Since the mechanical resistance of this kind of material is linked to its cell walls features, this research analyzed the cell walls thickness of silicon carbide ( $\mathrm{SiC}$ ) ceramic foams by X-ray microtomography. This technique is a powerful non destructive way to analyze the internal structure of any object, generating images (cross sections) by attenuation of the X-ray beam. The analyses of these images allow us to determine the samples structural parameters through specific software. The samples have pore densities of 30, 60 and 100 pore per inch (ppi). A Skyscan-1172 microtomograph, operated at $50 \mathrm{kV}$ high tension and $200 \mu \mathrm{A}$ current was utilized for the measurements. The spatial resolution obtained was $24.8 \mu \mathrm{m}$ and the measurement time was around 30 minutes for each sample. The analyses show that the cell walls of the 30 ppi sample have micropores. These micropores were observed at same images of 60 ppi cross sections too, but they were not observed at 100 ppi sample. It is probable that the cell walls of 100 ppi sample have micropores smaller than the achieved resolution.
\end{abstract}

XXXIV edition of the Brazilian Workshop on Nuclear Physics,

Foz de Iguaçu, Parana state, Brasil

5-10 June 2011

\footnotetext{
$1 \quad$ Speaker
} 


\section{Introduction}

Ceramic foams have a wide range of applications (heat exchangers, liquid metal filters, porous electrodes, composite of rocket nozzles, etc.) due their properties, such as high melting temperature, high porosity, low thermal conductivity and low density. Ceramic foams may or may not have micropores in their cell walls, depending on the manufacturing procedure. Since the mechanical resistance of this kind of material is linked to its cell walls features, this research analyzed the cell walls thickness of silicon carbide ( $\mathrm{SiC}$ ) ceramic foams by $\mathrm{X}$-ray microtomography.

$\mathrm{X}$-ray microtomography $(\mu-\mathrm{CT})$ is based on an X-ray beam that crosses the sample and is attenuated. The sample is rotated to measure attenuations at different angles. A reconstruction algorithm is then used to generate cross-sections of the sample's internal structure [1]. The most used algorithm is the Feldkamp algorithm [2]. Fig. 1 shows the general array of a microtomographic system. This technique had been used to analyze the internal structure of several kinds of materials, such as bones [3,4], rocks [5,6] and industrial foams [7,8].

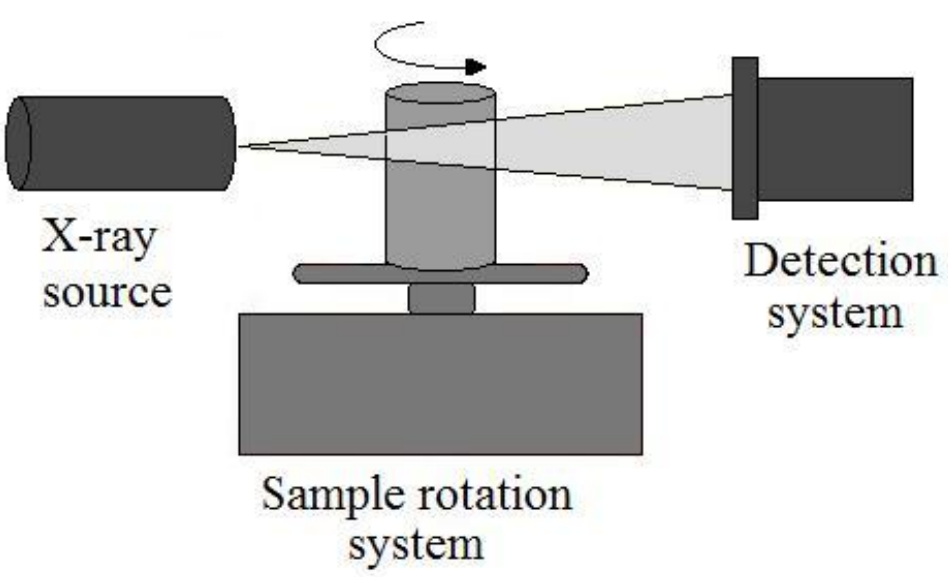

Figure 1 - General array of microtomographic system

\section{Experimental Procedure}

The samples analyzed are $\mathrm{SiC}$ ceramic foams with 30, 60 and 100 pores per inch (ppi).The measurements were performed at Petrobras Research Center (CENPES) with a Skyscan-1172 microtomograph. It was operated at $50 \mathrm{kV}$ high voltage for measurements with $24.8 \mu \mathrm{m}$ spatial resolution. The X-ray detector was a 4 megapixels CCD chamber fiber-optically coupled to scintillator. The total scanning time was 30 minutes for each sample. The cross sections reconstructions were performed using the NRecon software and 769 projections of each sample. The images were segmented and analyzed using the Imago software in order to obtain the cell walls thickness distribution. 


\section{Results}

Fig. 2 shows the raw microtomographic images for 30, 60 and 100 ppi SiC samples, respectively. In the 30 ppi sample micropores can be observed within the cell walls. In 60 ppi sample the micropores can be seen too, but only the better defined micropores remained after the segmentation process. In the 100 ppi sample the micropores were not observed.

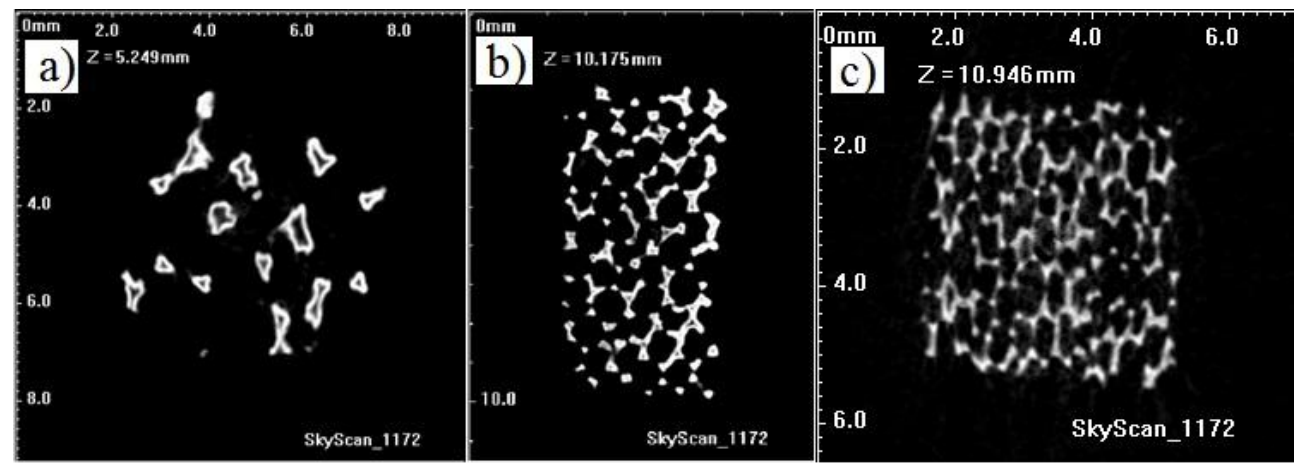

Figure 2 - Cross sections of samples with 30 ppi (a), 60 ppi (b) and 100 ppi (c)

Figures 3, 4 and 5 show the thickness distribution of the samples' cell walls for 30, 60 and 100 ppi samples, respectively.

In the 30 ppi sample $80 \%$ of the cells have thickness between $150 \mu \mathrm{m}$ and $250 \mu \mathrm{m}$. The most frequent value is $199.02 \mu \mathrm{m}$ (38.9\%). Due the high number of micropores within the cell walls one can say that this value represents the thickness of the cells' inner walls.

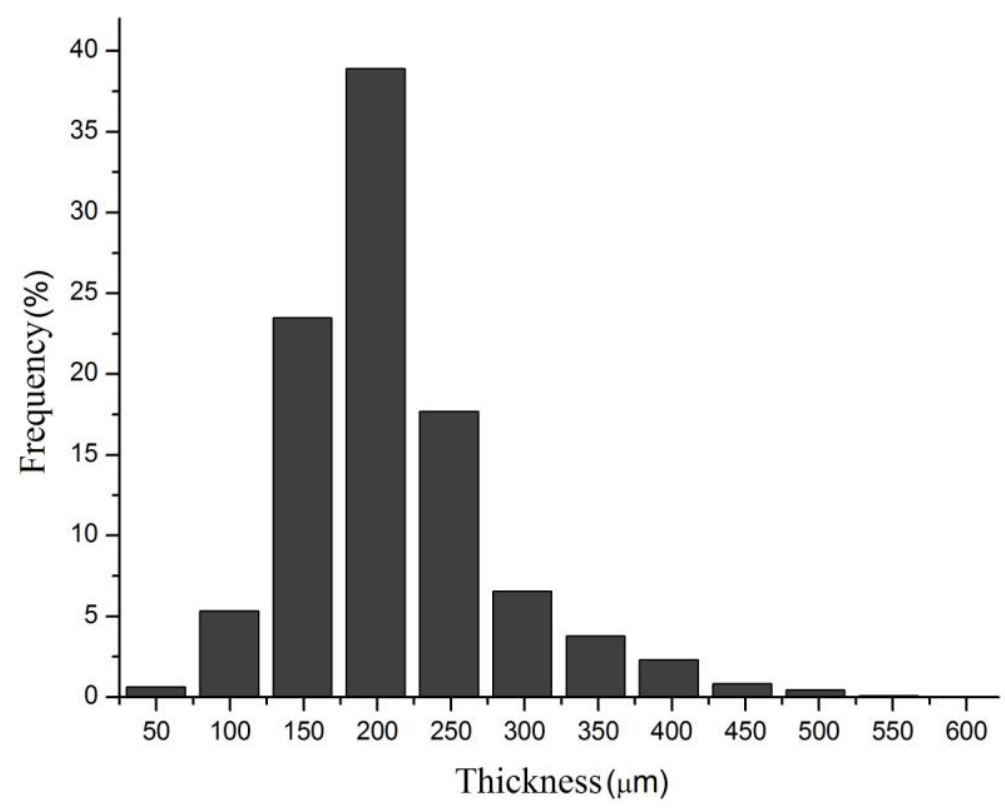

Figure 3 - Thickness distribution of 30 ppi sample 
In the 60 ppi sample $74.1 \%$ of the cells has thickness between 150 and $250 \mu \mathrm{m}$. The most frequent value is $199.02 \mu \mathrm{m}$ (37.2\%). In this sample the micropores can noticed but was barely measured. This means that the distribution shows the thickness of the whole cell wall.

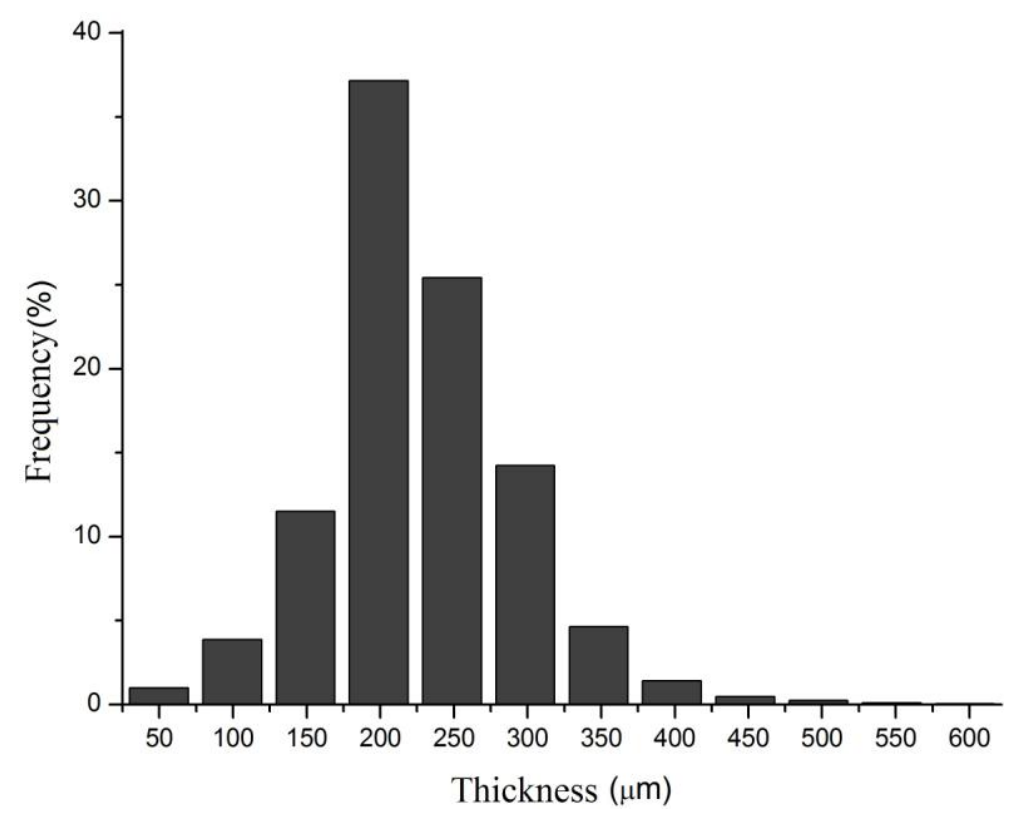

Figure 4 - Thickness distribution of 60 ppi sample

In the 100 ppi sample $90.2 \%$ of the cells has thickness between 100 and $200 \mu \mathrm{m}$. The most frequent value is $149.26 \mu \mathrm{m}(46.7 \%)$.

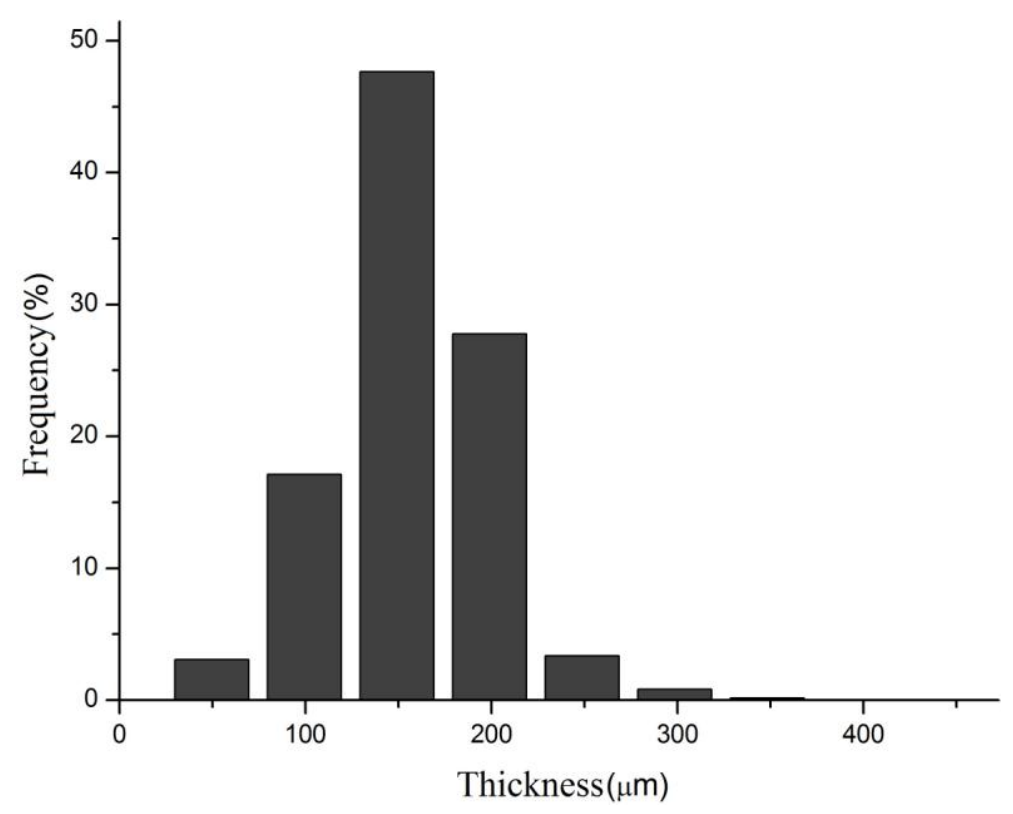

Figure 5 - Thickness distribution of 100 ppi sample 


\section{Conclusions}

The X-ray microtomography has shown to be a powerful tool for cell walls analyses of the considered material.

With the achieved resolution it was possible observe micropores in the cell walls of the 30 ppi sample and measure the thickness of the cells' inner walls.

For the other samples the whole thickness of the cell walls was measured. It is probable that using a better spatial resolution one can measure the thickness of the cells' inner walls either.

\section{Acknowledgments}

The authors thank CAPES and CNPq for financial support and CENPES/PETROBRAS for enable the measurements performing.

\section{References}

[1] A. C. Kak and M. Slaney, Principles of Computerized Tomographic Imaging. New York: IEEE Press, 1987.

[2] L. A. Feldkamp, L. C. Daves and J. W. Kress, Practical cone-beam algorithm, Journal of the Optical Society of America A, 1 (6), 612-619, 1984.

[3] M. Ding, A. Odgaard and I. Hvid, Accuracy of cancellous bone volume fraction measured by microCT scanning, Bone, 32, 323-326, 1999.

[4] D. M. L. Cooper, J. R. Matyas, M. A. Katzenberg and B. Hallgrimsson, Comparison of Microcomputed Tomographic and Microradiographic Measurements of Cortical Bone Porosity, Calcified Tissue International, 74, 437-447, 2002.

[5] C. R. Appoloni, C. P. Fernandes and C. R. Rodrigues. X-ray microtomography study of a sandstone reservoir rock, Nuclear Instruments and Methods in Physics Research A, 580, 629-623, 2007.

[6] K. Remeysen, R. Swennen. Application of microfocus computed tomography in carbonate reservoir characterization: Possibilities and limitations, Marine and Petroleum Geology, 25, 486-499, 2008.

[7] O.B. Olurin, M. Arnold, C. Körner, R.F. Singer. The investigation of morphometric parameters of aluminium foams using micro-computed tomography, Materials Science and Engineering A, 328, 334-343, 2002.

[8] C.R. Appoloni, C.P. Fernandes, M.D. Innocentini, A. Macedo. Ceramic Foams Porous Microstructure Characterization By X-ray Microtomography. Materials Research , 7, 557-564. 2004 